\title{
Risk Assessment of Drought Based on IEAPP-IDM in Qujing, Yunnan Province, China
}

\author{
Menghua Deng, ${ }^{1,2,3}$ Junfei Chen, ${ }^{1,2,3}$ Guiyun Liu, ${ }^{1,2,3}$ and Huimin Wang ${ }^{1,2,3}$ \\ ${ }^{1}$ State Key Laboratory of Hydrology-Water Resources and Hydraulic Engineering, Hohai University, Nanjing 210098, China \\ ${ }^{2}$ Institute of Management Science, Hohai University, Nanjing 210098, China \\ ${ }^{3}$ National Engineering Research Center of Water Resources Efficient Utilization and Engineering Safety, Hohai University, \\ Nanjing 210098, China
}

Correspondence should be addressed to Junfei Chen; chenjunfei@hhu.edu.cn

Received 2 October 2016; Accepted 12 December 2016

Academic Editor: Anthony R. Lupo

Copyright (C) 2016 Menghua Deng et al. This is an open access article distributed under the Creative Commons Attribution License, which permits unrestricted use, distribution, and reproduction in any medium, provided the original work is properly cited.

A new model for risk assessment of drought based on projection pursuit optimized by immune evolutionary algorithm and information diffusion method (IEAPP-IDM) was proposed. Due to the fact that drought risk assessment is a complex multicriteria and multilevel problem, the IEAPP-IDM model can project the multidimensional indicators of samples into one-dimension projection scores; then, the information carried by the projection scores was diffused into drought risk levels; finally, the drought disaster risk estimate was obtained. In the present study, Qujing was employed to assess the drought risk with the proposed model. The results showed that Xuanwei possessed higher risk, while Luliang and Zhanyi possessed lower risk. At the same time, the probability risk of drought in Malong and Luoping was increasing, while the probability risk of drought in in Qilin and Shizong was decreasing. The results obtained by the assessment model are consistent with the actual situation of Qujing and verify the model's effectiveness. The study can provide scientific reference in drought risk management for Qujing and other places of China.

\section{Introduction}

In recent years, extreme climate events, especially droughts, have occurred more frequently and caused large amounts of loss [1-3]. China is one of the countries that is most afflicted with serious drought disasters in the world. The annual average economic losses caused by droughts in China are over tens of billions of dollars from 2006 to 2014 [4]. Drought has become an important factor constraining China's agricultural productivity and sustainable development. The study area is located in the east of Yunnan Province and is influenced by East Asian monsoon and South Asian monsoon, resulting in fluctuating precipitation [5-7]. From 2009 to 2012, droughts had affected 453628.9 hectares of farmland and 3.48 million people in this area [8]. Consequently, evaluating drought risk is important for improving the prediction of drought and reducing the losses in the region.

In recent decades, some studies have been performed on the theory and methods for the risk evaluation of droughts, such as fuzzy analysis [9], copula [10], information diffusion
[11], and artificial neural networks [12]. Generally, drought risk assessment can be divided into qualitative assessment and quantitative assessment [13]. The quantitative assessment methods assess a potential risk of drought by means of several well-weighted indicators. For example, Chen and Yang [14] proposed fuzzy analytic network process (ANP) model to assess the risk of drought in Hunan province from 2007 to 2009. Jia and Pan [15] adopted wavelet transform method to assess the drought risk in Yunnan province of China. Hao et al. [16] adopted information diffusion model for drought risk assessment with the historic drought disaster data from 583 agrometeorological observations (1991-2009). Yin et al. [17] proposed GEPIC-V-R model to assess a large regional-scale crop drought risk. Quijano et al. [18] proposed an event-based approach to evaluate the probabilistic risk of agricultural drought under rain-fed conditions.

Remote sensing and geographic information systems (GIS) make it possible to evaluate drought over large areas and generate visual results [19]. Scholars have conducted some research in the field. For example, Wu et al. [20] applied 
the fuzzy clustering iterative model and GIS to analyze the agricultural drought vulnerability of 65 cities in the Yellow River basin in China. Han et al. [21] adopted vegetation temperature condition index (VTCI) to evaluate the drought in the Guanzhong Plain of China. Sahoo et al. [22] employed remote sensing derived vegetation condition index (VCI) for drought risk assessment in Dhar and Mewat of India. VicenteSerrano et al. [23] adopted long time series of remote sensing images and normalized difference vegetation index (NDVI) to evaluate the drought variability in semiarid regions worldwide.

However, there is an unavoidable fact that the remote sensing, geographic, and statistical information adopted to drought risk assessment have randomness, fuzziness, and nonuniformity characteristics. Therefore, uncertainty theories have been introduced into the drought risk assessment by some researchers, for example, fuzzy comprehensive evaluation [24], projection pursuit [25], comprehensive cloud model [26], and variable fuzzy sets (VFS) [27, 28]. There are some disadvantages to or deficiencies with these approaches. For example, the projection pursuit cannot well solve the multi-indicators and multiyears fuzzy synthetic risk evaluation of drought; the establishment of the relative membership function of the VFS depends on physical analysis and expert experience [29]. Taking into consideration these factors, there is a trend that combines different advantages of approaches with each other to construct new approaches. For example, Ouyang et al. [30] developed a composite method based on information diffusion method and bootstrap to estimate the drought risk; Li et al. [27] constructed an integrated model based on variable fuzzy sets and information diffusion to assess disaster risk. The optimization of projection pursuit is a complex and nonlinear problem with various restrictions. It is difficult to solve it with traditional optimization methods. Alternatively, the immune evolutionary algorithm (IEA), which is inspired from the mechanism of biological immune and evolution systems, has a good ability of global searching and diversiform memorizing and is capable of solving the optimization problem [31]. Besides, the algorithm has an advantage of fast convergence rate, requires few control parameters, and is more reliable for global optimization [32] and combinatorial optimization [33]. Therefore, in this paper, IEA was employed to solve the optimization problem of projection pursuit. Then, the information diffusion method (IDM) was adopted to transform the projection scores of different years into a fuzzy set to achieve the comprehensive risk evaluation of droughts. Therefore, the IEAAP-IDM model can be seen as an organic combination of the three theories.

The occurrence of drought is due to hazard-inducing environment, hazard-formative factors, and hazard-affected bodies. Therefore, in this study, drought was defined as a composite system of sensitivity of hazard-inducing environment, dangerousness of hazard-formative factors, and vulnerability of hazard-affected bodies. In the support of natural disaster risk assessment and IEAPP-IDM model, Qujing in Yunnan province was taken as a case study area. The objectives of the study are to (1) establish a drought risk assessment indicator system; (2) calculate the indicator weights objectively by means of projection direction vector; (3) develop the IEAPP-IDM model to evaluate the drought risk; (4) obtain the exceeding probability under different risk levels of drought and perform the comprehensive risk zoning map for drought risk management. The research can provide scientific reference for drought risk management by reasonable drought risk assessment.

\section{Overview of Study Area}

Qujing is located in the east of Yunnan province, between $102^{\circ} 42^{\prime} \mathrm{E}-104^{\circ} 50^{\prime} \mathrm{E}$ and $24^{\circ} 19^{\prime} \mathrm{N}-27^{\circ} 03^{\prime} \mathrm{N}$. It is one of the important economic cities in Yunnan province, administratively divided into 9 counties, including Qilin, Zhanyi, Luoping, Fuyuan, Shizong, Luliang, Huize, Malong, and Xuanwei (Figure 1). It covers an area of $2.89 \times 10^{4} \mathrm{~km}^{2}(\sim 13.63 \%$ of Yunnan province), and its population is 5.85 million. The main climate type of the study area is typical subtropical plateau monsoon. The annual mean temperature is $14.5^{\circ} \mathrm{C}$. The average annual precipitation is around $1000 \mathrm{~mm}$. The water resource is sufficient from May to October but is deficient from November to April. In recent years, localized drought disasters have occurred frequently and caused huge losses. Thus, drought has become one of the most important factors that restrict the development of Qujing.

\section{Data and Methods}

3.1. Data Sources. The data were collected from Yunnan Statistical Yearbook, Yunnan Water Conservancy Statistics Yearbook, Yunnan Water Resource Bulletin, and Yunnan Drought Briefing. Statistics were provided by the Qujing Flood Control and Drought Relief Headquarters.

3.2. IEAPP. The basic idea of projection pursuit (PP) is to project data from high dimension into one, two, or three dimensions in accordance with certain reconstruction rules [34]. The PP model can analyze the structural characters of observed samples with the projection objective function; determine the indicator weights in an objective way with the projection direction; and obtain fairly stable results [35]. However, the optimization of projection direction is the key and difficult point to the application of the model. Immune evolutionary algorithm (IEA) is a global optimization method, which can improve the performance and increase the convergent speed, and is an effective method to solve the optimization problem [36]. Thus, IEA is employed to solve the projection direction optimization problem. The steps of the projection pursuit optimized by immune evolutionary algorithm (IEAPP) are as follows.

(1) Constructing Projection Data. Suppose there are $n$ assessment samples and $m$ indicators and $X_{i j}(i=1,2, \ldots, n ; j=$ $1,2, \ldots, m)$ denotes the value of index $j$ in sample $i$. Due to the difference in indicator values and units, it is necessary to normalize the samples. For the greatest large evaluation value, 


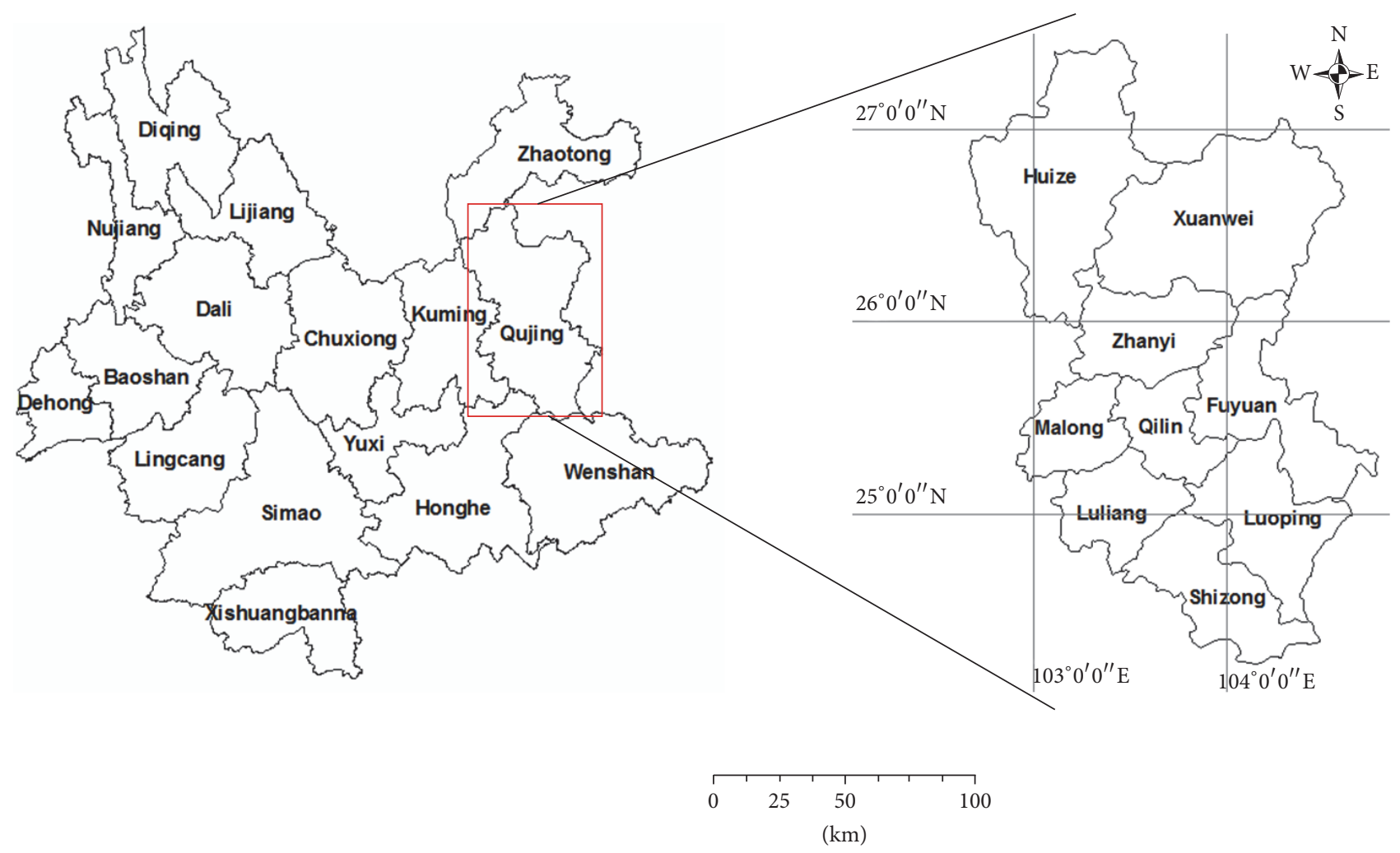

Figure 1: Geographic location of Qujing in Yunnan Province.

(1) should be employed, and, for the greatest small evaluation value, (2) should be employed:

$$
\begin{aligned}
& x_{i j}=\frac{X_{i j}-X_{\min j}}{X_{\max j}-X_{\min j}}, \\
& x_{i j}=\frac{X_{\max j}-X_{i j}}{X_{\max j}-X_{\min j}},
\end{aligned}
$$

where $X_{\max j}$ and $X_{\min j}$ are the maximum and the minimum index $j$ of all samples, respectively, and $x_{i j}$ is the normalized value.

(2) Constructing Projection Objective Function. Suppose $a=$ $\left\{a_{1}, a_{2}, \ldots, a_{m}\right\}$ is the normalized projection vector. In order to project the high-dimensional indicator value of samples into one dimension, (3) should be employed:

$$
z(i)=\sum_{j=1}^{m} a_{j} x_{i j}, \quad i=1,2, \ldots, n,
$$

where $z(i)$ is the projection score. Then, the projection objective function can be established as follows:

$$
Q(a)=S_{z} D_{z} \text {, }
$$

where $S_{z}$ is the standard deviation (see (5)) and $D_{z}$ is the density of projection scores (see (6)).

$$
\begin{gathered}
S_{z}=\sqrt{\frac{\sum_{i=1}^{n}(z(i)-E(z))^{2}}{n-1}}, \\
D_{z}=\sum_{i=1}^{n} \sum_{j=1}^{n}\left(R-r_{i j}\right) \cdot u\left(R-r_{i j}\right) .
\end{gathered}
$$

where $E(z)$ is the mean value of $\{z(i) \mid i=1,2, \ldots, n\} ; R$ is the density window radius; $u\left(R-r_{i j}\right)$ is the unit leap function, when $R-r_{i j} \geq 0, u\left(R-r_{i j}\right)=1$, otherwise, $u\left(R-r_{i j}\right)=0$.

(3) Optimization of the Projection Objective Function. The projection objective function $Q(a)$ only varies with the projection direction $a$. Different $a$ represents different data structure or characteristics. The optimal projection direction $\left(a^{*}\right)$ can be resolved by optimizing the following model:

$$
\begin{array}{ll}
\max & Q(a)=S_{z} D_{z} \\
\text { s.t. } & \sum_{j=1}^{m} a_{j}^{2}=1 .
\end{array}
$$

The above model is a nonlinear optimization problem and is difficult to be solved with traditional optimization methods. As a result of IEA being capable of solving global 


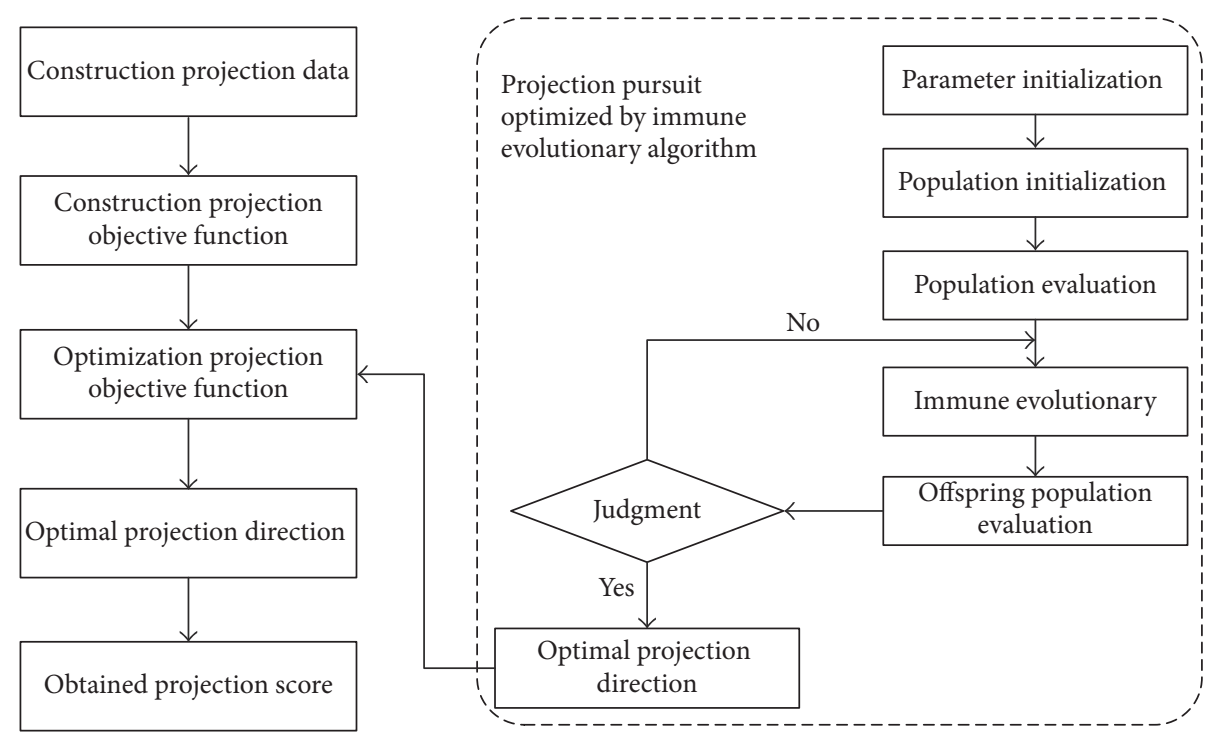

Figure 2: Flow diagram of IEAPP.

optimization problem effectively, in this study, IEA is combined to obtain the optimal projection direction $a^{*}$.

(4) Obtaining the Projection Scores. The optimal projection direction $a^{*}$ reflects the importance of indicators. Due to $a^{*}$ being a unit vector and $a_{1}^{2}+a_{2}^{2}+\cdots+a_{m}^{2}=1$, so $a_{1}^{2}, a_{2}^{2}, \ldots, a_{m}^{2}$ can be taken as indicator weight in an objective way. Then, the projection score $z^{*}(i)$ can be calculated by (3). Figure 2 shows the flow of the projection pursuit optimized by IEA.

3.3. IDM. Information diffusion is a set-valued fuzzy mathematical method, which can dispose incomplete information of samples [37]. The method can transform an observed data into a fuzzy set to improve the evaluation accuracy [38]. In this paper, we employed IDM to diffuse the projection scores of the observed sample into the fuzzy set and obtain the comprehensive drought risk values. There are many types of information diffusion methods, such as the normal information diffusion method, logarithmic diffusion, and double exponential jump diffusion. Hung and Wang [39] demonstrated that the normal information diffusion method is better than logarithmic and exponential diffusion method under the small sample size condition. Therefore, in this paper, the normal information diffusion method is adopted.

Let $Y=\left\{y_{1}, y_{2}, \ldots, y_{n}\right\}$ be a sample set, $y_{i}(i=1,2, \ldots, n)$ is the observed value, $U=\left\{u_{1}, u_{2}, \ldots, u_{s}\right\}$ is the discrete universe, and $u_{l}(l=1,2, \ldots, s)$ is a value in $U$. The method turns single observed value $y_{i}$ into set-valued sample $u_{l}$ as follows:

$$
\begin{aligned}
f_{y_{i}}\left(u_{l}\right)=\frac{1}{h \sqrt{2 \pi}} \exp \left[-\frac{\left(y_{i}-u_{l}\right)}{2 h^{2}}\right], \\
\quad(i=1,2, \ldots, n, l=1,2, \ldots, s),
\end{aligned}
$$

where $h$ is the diffusion coefficient, calculated by

$$
h= \begin{cases}0.8146(b-a), & n=5 \\ 0.5690(b-a), & n=6 \\ 0.4560(b-a), & n=7 \\ 0.3860(b-a), & n=8 \\ 0.3362(b-a), & n=9 \\ 0.2986(b-a), & n=10 \\ \frac{0.6851(b-a)}{(n-1)}, & n \geq 11\end{cases}
$$

where $a=\min _{1 \leq i \leq n}\left\{y_{i}\right\}$ and $b=\max _{1 \leq i \leq n}\left\{y_{i}\right\}$.

In order to ensure the same status of each set-valued sample, it is necessary to normalize the diffusion function $f_{y_{i}}\left(u_{l}\right)$; suppose

$$
C_{i}=\sum_{l=1}^{s} f_{y_{i}}\left(u_{l}\right)
$$

Then, the normalized diffusion function $\mu_{y_{i}}\left(u_{l}\right)$ can be obtained by

$$
\mu_{y_{i}}\left(u_{l}\right)=\frac{f_{y_{i}}\left(u_{l}\right)}{C_{i}}
$$

Furthermore, suppose $q\left(u_{l}\right)=\sum_{i=1}^{n} \mu_{y_{i}}\left(u_{l}\right)$ and $=$ $\sum_{l=1}^{s} q\left(u_{l}\right)$; the probability of samples that fall in $u_{l}$ can be obtained by

$$
p\left(u_{l}\right)=\frac{q\left(u_{l}\right)}{Q},
$$


Finally, the exceeding probability $P\left(u_{l}\right)$ can be calculated as follows:

$$
P\left(u_{l}\right)=\sum_{k=l}^{s} p\left(u_{k}\right) .
$$

3.4. Steps of Drought Risk Assessment Model. The basic idea of drought risk assessment model based on IEAPP-IDM is as follows. On the basis of drought risk assessment indicator system, firstly, the optimal projection scores are calculated through the IEAPP model. Then, the information carried by the projection scores is diffused to the drought risk levels through the information diffusion method. Finally, the probability risk value or the drought risk estimate is calculated.

The main steps of drought risk assessment based on IEAPP-IDM model are as follows.

Step 1. Sample analysis and selection of assessment indicators are conducted for the evaluation of drought risk.

Step 2. Calculate the optimal projection direction and projection scores based on the IEAPP model.

Step 3. Calculate the exceeding probability or the drought probability risk estimation based on the IDM model.

Step 4. Draw the comprehensive risk zoning maps.

Exceeding probability is the value of drought risk, reflecting the corresponding exceeding probability of drought risk under different drought risk levels. In other words, it indicates the recurrence interval years $(N)$ under different drought risk levels. The relationship between the exceeding probability and recurrence interval years $(N)$ can be expressed as $N=$ $1 / P\left(u_{l}\right)$.

\section{Results and Discussion}

4.1. Indicator System. According to the natural disaster system theory and the actual situation of Qujing, the indicators were chosen from dangerousness of hazard-formative factors, sensitivity of hazard-inducing environment, and vulnerability of hazard-affected bodies. Therefore, the risk evaluation indicator system of drought was established in Qujing (see Figure 3). The entire indicator system was divided into dangerousness, sensitivity, and vulnerability of the three subsystems.

The dangerousness of hazard-formative factors describes the abnormal degree of nature and society. Among them, extreme precipitation and temperature are the main cause of drought. Generally, the higher dangerousness of hazardformative factors the easier appearance of drought. That is, precipitation anomaly percentage $\left(I_{11}: \%\right)$, homogenization of precipitation and temperature $\left(I_{12}\right)$, soil moisture from November to April $\left(I_{13}: \%\right)$, and per capita water resources $\left(I_{14}: \mathrm{m}^{3} /\right.$ person) are chosen as the indicators of the dangerousness subsystem.

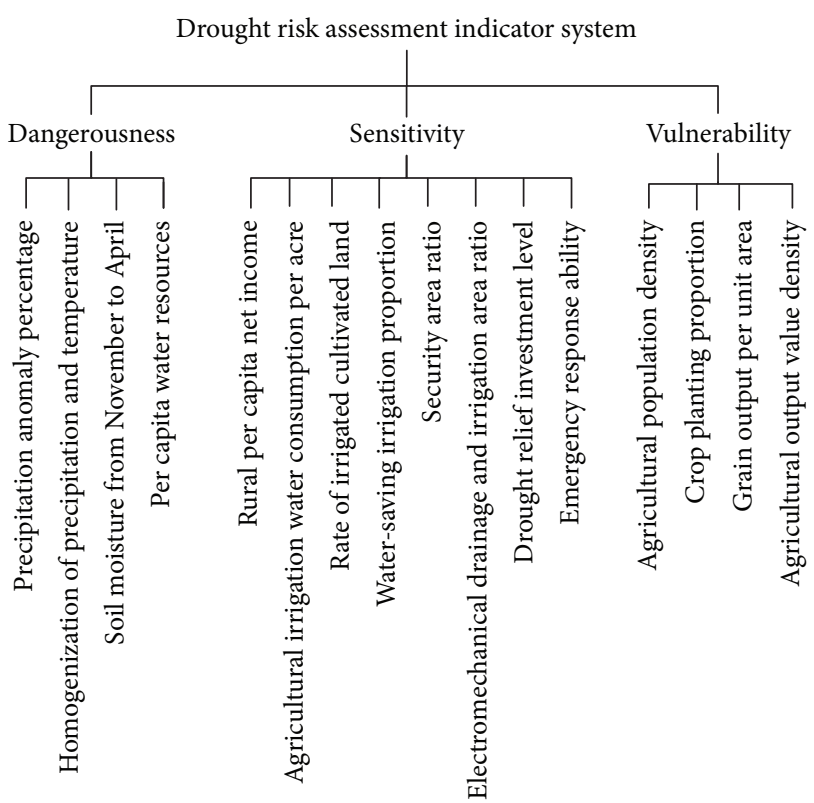

FIGURE 3: Indicator system of drought risk evaluation.

The sensitivity of hazard-inducing environment mainly describes the responsiveness to drought. The environment includes climate, soil, economic development level, basic irrigation facilities, and other nature, social, economic, and ecosystem. The greater the sensitivity, the larger the losses caused by drought. The rural per capita net income $\left(I_{21}\right.$ : Yuan), agricultural irrigation water consumption per acre $\left(I_{22}: \mathrm{m}^{3} / \mathrm{mu}\right)$, rate of irrigated cultivated land $\left(I_{23}: \%\right)$, watersaving irrigation proportion $\left(I_{24}: \%\right)$, security area ratio $\left(I_{25}\right.$ : $\%)$, electromechanical drainage and irrigation area ratio $\left(I_{26}\right.$ : $\%)$, drought relief investment level $\left(I_{27}: \%\right)$, and emergency response ability $\left(I_{28}\right)$ are selected to describe the sensitivity.

The vulnerability of hazard-affected bodies reflects the antidisaster ability. The higher the value density of hazardaffected bodies, the greater the loss. Agricultural population density $\left(I_{31}\right)$, crop planting proportion $\left(I_{32}: \%\right)$, grain output per unit area $\left(I_{33}: \mathrm{kg} / \mathrm{mu}\right)$, and agricultural output value density $\left(I_{34}\right.$ : ten-thousand $\left./ \mathrm{km}^{2}\right)$ are chosen to describe the vulnerability.

4.2. Risk Assessment of Drought Based on IEAPP-IDM. Based on the drought risk assessment indicator system and IEAPPIDM model, firstly, the optimal projection direction and projection scores in Qujing were calculated; then, the fuzzy relationship between projection score and drought risk level was established; finally, the comprehensive risk evaluation was obtained and the risk zoning map was drawn. For demonstration purposes, Qilin has been chosen as an example to discuss the risk assessment of drought based on IEAPPIDM model in detail.

(1) The indicator values of Qilin from 2000 to 2010 are shown in Table 1.

(2) Calculate the optimal projection direction and the projection scores 
TABLE 1: Values of indicator system for drought risk evaluation in Qilin.

\begin{tabular}{|c|c|c|c|c|c|c|c|}
\hline Year & $\begin{array}{c}\text { Precipitation anomaly } \\
\text { percentage }(\%)\end{array}$ & $\begin{array}{c}\text { Per capita water } \\
\text { resources }\left(\mathrm{m}^{3} / \text { person }\right)\end{array}$ & $\begin{array}{c}\text { Rural per capita net } \\
\text { income (Yuan) }\end{array}$ & $\begin{array}{c}\text { Water-saving irrigation } \\
\text { proportion }(\%)\end{array}$ & $\begin{array}{c}\text { Security area } \\
\text { ratio }(\%) \\
\end{array}$ & $\begin{array}{c}\text { Crop planting } \\
\text { proportion (\%) }\end{array}$ & \\
\hline 2000 & -10.58 & 852.43 & 2410 & 0.49 & 38.66 & 23.69 & $\ldots$ \\
\hline 2001 & 30.18 & 860.01 & 2510 & 0.56 & 39.65 & 23.30 & $\ldots$ \\
\hline 2002 & 8.74 & 823.62 & 2613 & 0.58 & 40.87 & 22.99 & $\ldots$ \\
\hline 2003 & -11.47 & 732 & 2743 & 0.59 & 41.48 & 22.94 & $\ldots$ \\
\hline 2004 & -11.47 & 761.55 & 2999 & 0.59 & 46.31 & 20.74 & $\ldots$ \\
\hline 2005 & -11.47 & 674.64 & 3207 & 0.60 & 47.40 & 20.42 & $\ldots$ \\
\hline 2006 & -11.47 & 710.83 & 3528 & 0.59 & 48.66 & 20.08 & $\ldots$ \\
\hline 2007 & 19.19 & 805.15 & 3847 & 0.59 & 48.12 & 20.33 & $\ldots$ \\
\hline 2008 & 15.20 & 762.81 & 4540 & 0.62 & 47.85 & 20.59 & $\ldots$ \\
\hline 2009 & -22.19 & 344.22 & 5017 & 0.68 & 45.74 & 21.54 & $\ldots$ \\
\hline 2010 & 5.35 & 455.41 & 5569 & 0.70 & 38.66 & 21.62 & $\ldots$ \\
\hline
\end{tabular}

TABLE 2: Projection scores from 2000 to 2010 of Qilin.

\begin{tabular}{lccc}
\hline Year & Projection scores & Year & Projection scores \\
\hline 2000 & 1.726206 & 2006 & 1.305228 \\
2001 & 1.432224 & 2007 & 0.898119 \\
2002 & 1.433793 & 2008 & 1.47205 \\
2003 & 1.613357 & 2009 & 2.504377 \\
2004 & 0.898118 & 2010 & 2.239686 \\
2005 & 1.004282 & & \\
\hline
\end{tabular}

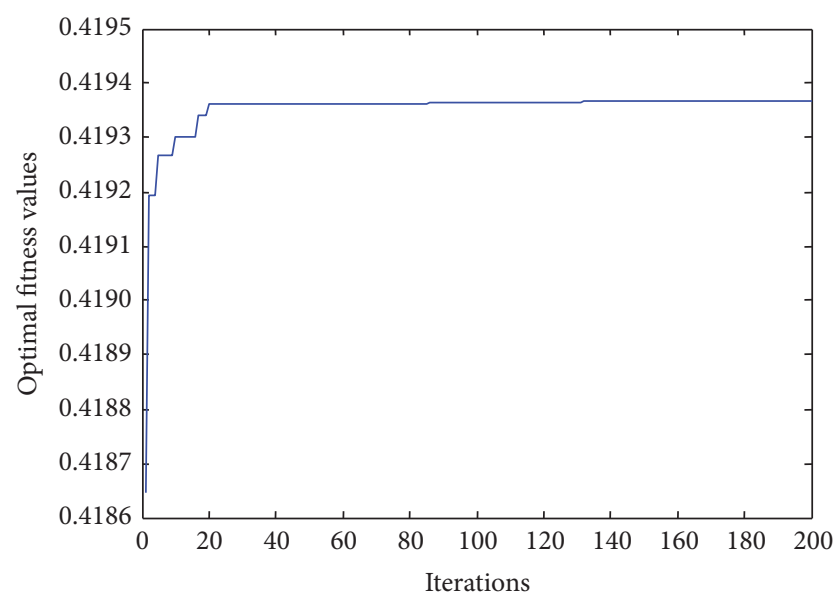

FIGURE 4: The optimization of projection objective function.

Figure 4 shows the process of how to obtain the optimal fitness value, which is equal to the best value of the projection objective function. As is shown in Figure 4, the best value of projection objective function is 0.419366 and the corresponding optimal projection direction $\left(a^{*}\right)$ is $a^{*}=(0.08,0.354$, $0.11,0.401,0.029,0.017,0.371,0.024,0.078,0.338,0.473,0.284$, $0.041,0.238,0.246,0.08)$.

The projection scores of samples in Qilin are calculated in Table 2.

(3) Calculate the exceeding probability

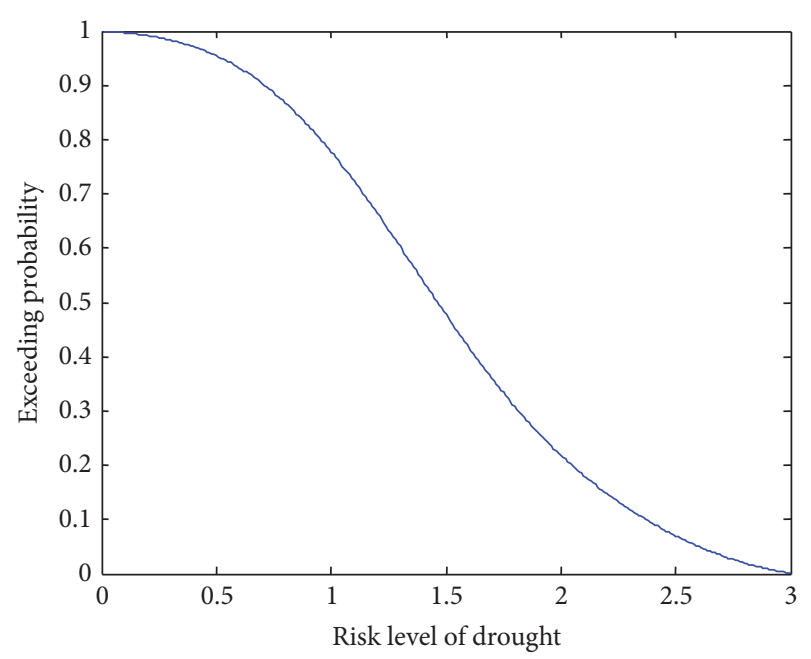

FIGURE 5: The exceeding probability curve of drought to drought risk level in Qilin.

According to the actual situation and the range of projection scores, the domain of drought risk level is set to $[0,3]$ and the discrete universe is $[0,0.01,0.02,0.03, \ldots, 2.99,3]$. The exceeding probability under different values of drought risk level (see Table 3 ) and exceeding probability curve to drought risk level (see Figure 5) of Qilin are obtained.

The results illustrate the risk estimation, that is, the exceeding probability of drought risk level, which indicates the risk level of drought impacts occurring with a corresponding frequency probability. For example, the exceeding probability is 0.050252 when the risk level is 2.5 , that means drought exceeding the risk level of 2.5 occurs every 19.90 $\left(N=1 / P\left(u_{l}\right)\right)$ years. The results also illustrate the exceeding probability is greater than 0.508417 when the drought risk level is below 1.45 . It means every $1-2$ years there will be a drought in the risk level of $[0,1.45]$. Similarly, the probability of drought exceeding the risk level of 2.35 is 0.105279 , indicating that drought exceeding that intensity occurs every 9-10 years. 
TABLE 3: The exceeding probability of drought risk in Qilin.

\begin{tabular}{|c|c|c|c|c|c|c|c|}
\hline Risk level & $\begin{array}{l}\text { Exceeding } \\
\text { probability }\end{array}$ & Risk Level & $\begin{array}{l}\text { Exceeding } \\
\text { probability }\end{array}$ & Risk level & $\begin{array}{l}\text { Exceeding } \\
\text { probability }\end{array}$ & Risk level & $\begin{array}{l}\text { Exceeding } \\
\text { probability }\end{array}$ \\
\hline 0.01 & 1 & 0.8 & 0.867955 & 1.6 & 0.416944 & 2.4 & 0.092722 \\
\hline 0.05 & 0.998765 & 0.85 & 0.847743 & 1.65 & 0.388017 & 2.45 & 0.080952 \\
\hline 0.1 & 0.996841 & 0.9 & 0.825864 & 1.7 & 0.360126 & 2.5 & 0.069956 \\
\hline 0.15 & 0.99441 & 0.95 & 0.802375 & 1.75 & 0.333378 & 2.55 & 0.059724 \\
\hline 0.2 & 0.991376 & 1 & 0.777357 & 1.8 & 0.307852 & 2.6 & 0.050252 \\
\hline 0.25 & 0.987634 & 1.05 & 0.75092 & 1.85 & 0.283593 & 2.65 & 0.041538 \\
\hline 0.3 & 0.983071 & 1.1 & 0.723196 & 1.9 & 0.260619 & 2.7 & 0.033575 \\
\hline 0.35 & 0.977571 & 1.15 & 0.694341 & 1.95 & 0.238919 & 2.75 & 0.026357 \\
\hline 0.4 & 0.971013 & 1.2 & 0.664532 & 2 & 0.218462 & 2.8 & 0.019869 \\
\hline 0.45 & 0.963278 & 1.25 & 0.633965 & 2.05 & 0.199201 & 2.85 & 0.01409 \\
\hline 0.5 & 0.954252 & 1.3 & 0.602849 & 2.1 & 0.181075 & 2.9 & 0.008993 \\
\hline 0.55 & 0.943827 & 1.35 & 0.571402 & 2.15 & 0.16402 & 2.95 & 0.004544 \\
\hline 0.6 & 0.931909 & 1.4 & 0.53985 & 2.2 & 0.14797 & 3 & 0.00007 \\
\hline 0.65 & 0.918415 & 1.45 & 0.508417 & 2.25 & 0.132864 & & \\
\hline 0.7 & 0.903283 & 1.5 & 0.47732 & 2.3 & 0.118649 & & \\
\hline 0.75 & 0.88647 & 1.55 & 0.446767 & 2.35 & 0.105279 & & \\
\hline
\end{tabular}

TABLE 4: Drought exceeding probability under different values of drought risk level in Qujing.

\begin{tabular}{|c|c|c|c|c|c|c|c|c|c|}
\hline \multirow{2}{*}{ County } & \multicolumn{9}{|c|}{ Drought risk level } \\
\hline & $10 \% I$ & $20 \% I$ & $30 \% I$ & $40 \% I$ & $50 \% I$ & $60 \% I$ & $70 \% I$ & $80 \% I$ & $90 \% I$ \\
\hline Qilin & 0.983071 & 0.931909 & 0.825864 & 0.664532 & 0.47732 & 0.307852 & 0.181075 & 0.092722 & 0.033575 \\
\hline Luliang & 0.921317 & 0.813096 & 0.685131 & 0.548579 & 0.415574 & 0.296371 & 0.19632 & 0.115304 & 0.050832 \\
\hline Malong & 0.937312 & 0.853105 & 0.753448 & 0.643408 & 0.526993 & 0.407551 & 0.289479 & 0.178794 & 0.081647 \\
\hline Shizong & 0.992931 & 0.96363 & 0.885809 & 0.74531 & 0.562986 & 0.381655 & 0.231758 & 0.119136 & 0.042311 \\
\hline Luoping & 0.979133 & 0.93068 & 0.843208 & 0.716172 & 0.565602 & 0.416658 & 0.287396 & 0.179445 & 0.085369 \\
\hline Fuyuan & 0.934763 & 0.840793 & 0.729207 & 0.604934 & 0.466484 & 0.318456 & 0.181193 & 0.079881 & 0.023437 \\
\hline Zhanyi & 0.942816 & 0.838058 & 0.689776 & 0.521581 & 0.366493 & 0.245332 & 0.156528 & 0.088467 & 0.03602 \\
\hline Huize & 0.969277 & 0.899918 & 0.790613 & 0.661373 & 0.531655 & 0.402499 & 0.2726 & 0.153436 & 0.060459 \\
\hline Xuanwei & 0.98318 & 0.939145 & 0.855353 & 0.730428 & 0.577193 & 0.419267 & 0.278665 & 0.162169 & 0.068552 \\
\hline
\end{tabular}

Repeating the above methods and processes, the exceeding probability under different drought risk levels in other counties are calculated (see Table 4).

In this study, the drought risk level is divided into 9 levels. The probability risks of drought under each drought risk level may be obtained. The result in Table 4 illustrates the risk estimation of drought in Qujing. For example, the exceeding probabilities of $10 \% I$ are more than 0.92 in all counties in Qujing, that is to say that risk level of drought is normal in Qujing. In other words, the risk level of $10 \%$ I is small and has little impact.

\section{(4) Draw the maps of drought risk in Qujing}

The comprehensive risk zoning maps of drought in Qujing are drawn in Figure 6. (a), (b), (c), and (d) illustrate the risk levels of $30 \% I, 40 \% I, 50 \% I$, and $60 \% I$, respectively.

Compared to the different values of drought risk level, for example, in the risk level of $50 \% \mathrm{I}$, the probability risk of drought in Xuanwei, Luoping, and Shizong is the highest. Table 4 also shows that the probability risk in these three areas are more than 0.562986 and recurrence interval years are less than 1.7, that is to say, these areas will have a drought exceeding the value of $50 \%$ I every $1-2$ years. Under the same drought risk level, the recurrence interval years of Zhanyi are 2.7, Qilin, Luliang, and Fuyuan are 2.1 to 2.4, and Malong and Huize are 1.9. From the counties under different drought risk level, the probability risk of drought in Xuanwei, Luoping, and Shizong is higher than other counties, while Zhanyi and Luliang is lower than other counties.

\section{Conclusions}

In this study, a new model for risk assessment of drought based on projection pursuit optimized by immune evolutionary algorithm and information diffusion method (IEAPPIDM) was developed. Then, based on the natural disaster system theory and integrated risk factors of drought, including sensitivity of hazard-inducing environment, dangerousness of hazard-formative factors, and vulnerability of hazard-affected bodies, the indicator system of drought risk assessment was established. The model can deal with the uncertainty, fuzziness, and inaccuracy problem of the 

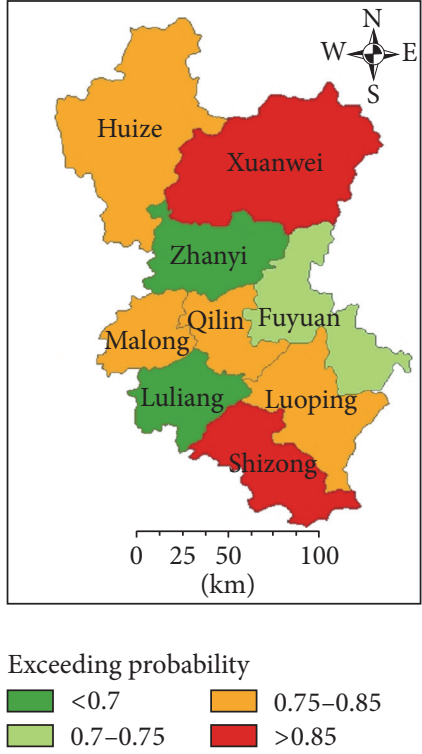

(a)
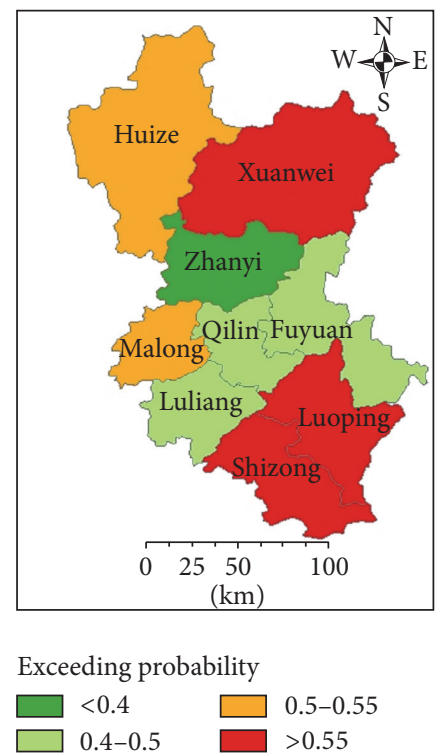

(c)
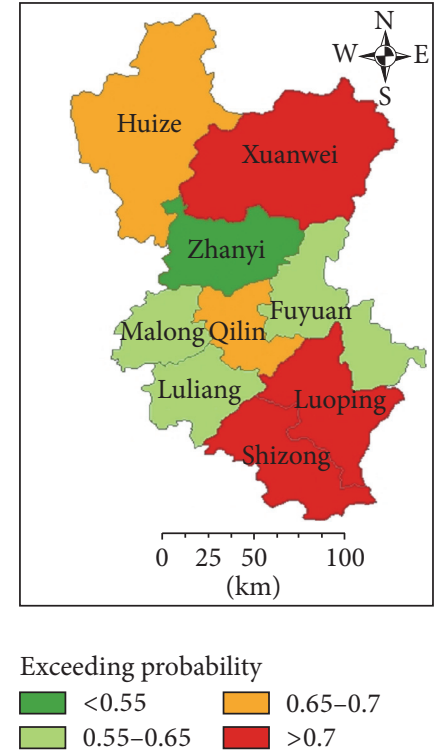

(b)

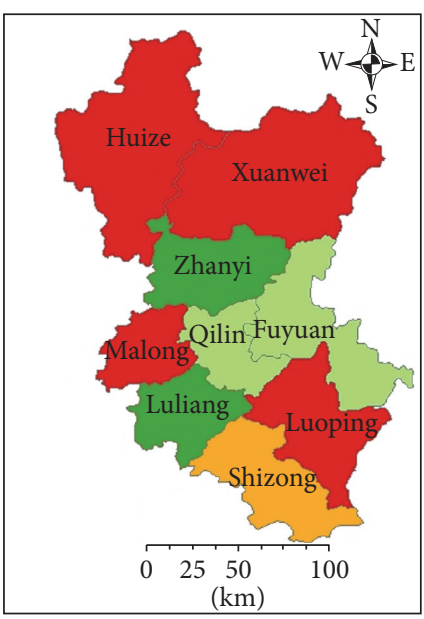

Exceeding probability

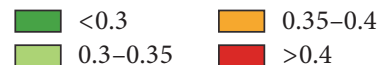

(d)

Figure 6: Maps of drought risk in Qujing.

drought risk assessment and can obtain fairly stable results. Based on the IEAPP-IDM model and the indicator system, Qujing in Yunnan province was taken as a case study area. The results showed that, in the same level of drought risk, the exceeding probability of Xuanwei was maintained at a high level, while the exceeding probability of Luliang and Zhanyi was maintained at a low level. At the same time, the probability risk of drought in Malong and Luoping is increasing, while the probability risk of drought in Qilin and Shizong is decreasing. The results are consistent with the actual situation of Qujing and can provide reference for the emergency management department; meanwhile, the results have important significance for the planning and development of disaster insurance programs of the insurance company. However, due to the complexity of risk evaluation of drought, it is necessary to further study the formation mechanism, indicator system, and risk management of regional drought.

\section{Competing Interests}

The authors declare that there are no competing interests regarding the publication of this paper.

\section{Acknowledgments}

This research was supported by the State Key Program of National Nature Science Foundation of China (Grant no. 
71433003), the Major Program of National Social Science Foundation of China (Grant no. 12\&ZD214), 2014 Jiangsu Province Qing Lan Project of China, and the Fundamental Research Funds for the Central Universities (Grant no. 2016B46414).

\section{References}

[1] L. Liang, S.-H. Zhao, Z.-H. Qin et al., "Drought change trend using MODIS TVDI and its relationship with climate factors in China from 2001 to 2010," Journal of Integrative Agriculture, vol. 13, no. 7, pp. 1501-1508, 2014.

[2] L. Cheng, J. Jin, J. Li, Z. Wang, L. Li, and X. Yuan, "Advance in the study of drought frequency analysis," Advances in Water Science, vol. 24, no. 2, pp. 296-302, 2013.

[3] J. H. Wan, J. Lyu, H. P. Liu, J. Liu, Z. Yang, and F. Chen, "Drought-flood variation characteristics and trends in arid Northwestern China during 1470-2008," Advance in Water Science, vol. 25, no. 5, pp. 625-631, 2014 (Chinese).

[4] State Flood Control and Drought Relief Headquarters and Ministry of Water Resources of China, Bulletin of Flood and Drought Disasters in China, China Water \& Power Press, Beijing, China, 2014 (Chinese).

[5] Z. Chi, Z. Du, Z. Chen et al., "Analyses on meteorological elements and general circulation of drought in Guizhou Province in Autumn-Winter-Spring from 2009 to 2010," Plateau Meteorology, vol. 31, no. 1, pp. 176-184, 2012.

[6] J. Yang, D. Gong, W. Wang, M. Hu, and R. Mao, "Extreme drought event of 2009/2010 over southwestern China," Meteorology and Atmospheric Physics, vol. 115, no. 3-4, pp. 173-184, 2012.

[7] H. Yang, J. Song, H. M. Yan et al., "Cause of the severe drought in Yunnan Province during winter of 2009 to 2010," Climatic and Environmental Research, vol. 17, no. 3, pp. 315-326, 2012 (Chinese).

[8] Y. B. Gong, J. G. Zhang, G. F. Liu et al., "Research on the drought characteristics in Qujing City base on the SPI and R/S analysis," Agricultural Research in the Arid Areas, vol. 33, no. 3, pp. 273277, 2015 (Chinese).

[9] S. Huang, J. Chang, G. Leng, and Q. Huang, "Integrated index for drought assessment based on variable fuzzy set theory: a case study in the Yellow River basin, China," Journal of Hydrology, vol. 527, pp. 608-618, 2015.

[10] D.-D. Zhang, D.-H. Yan, F. Lu, Y.-C. Wang, and J. Feng, "Copula-based risk assessment of drought in Yunnan province, China," Natural Hazards, vol. 75, no. 3, pp. 2199-2220, 2014.

[11] C. F. Huang, X. L. Liu, G. X. Zhou et al., "Agricultural natural disaster risk assessment method according to the historic disaster data," Journal of Natural Disaster, vol. 7, no. 2, pp. 4-12, 1998 (Chinese).

[12] M. Rezaeianzadeh, A. Stein, and J. P. Cox, "Drought forecasting using Markov chain model and artificial neural networks," Water Resources Management, vol. 30, no. 7, pp. 2245-2259, 2016.

[13] K. Unami, F. K. Abagale, M. Yangyuoru, A. H. M. B. Alam, and G. Kranjac-Berisavljevic, "A stochastic differential equation model for assessing drought and flood risks," Stochastic Environmental Research and Risk Assessment, vol. 24, no. 5, pp. 725-733, 2010.

[14] J. F. Chen and Y. Yang, "A fuzzy ANP-based approach to evaluate region agricultural drought risk," Procedia Engineering, vol. 23, pp. 822-827, 2011.
[15] H. Jia and D. Pan, "Drought risk assessment in Yunnan province of China based on wavelet analysis," Advances in Meteorology, vol. 2016, Article ID 1579415, 10 pages, 2016.

[16] L. Hao, X. Zhang, and S. Liu, "Risk assessment to China's agricultural drought disaster in county unit," Natural Hazards, vol. 61, no. 2, pp. 785-801, 2012.

[17] Y. Yin, X. Zhang, D. Lin, H. Yu, J. Wang, and P. Shi, "GEPICV-R model: a GIS-based tool for regional crop drought risk assessment," Agricultural Water Management, vol. 144, pp. 107119, 2014.

[18] J. A. Quijano, M. A. Jaimes, M. A. Torres et al., "Event-based approach for probabilistic agricultural drought risk assessment under rainfed conditions," Natural Hazards, vol. 76, no. 2, pp. 1297-1318, 2015.

[19] A.-A. Belal, H. R. El-Ramady, E. S. Mohamed, and A. M. Saleh, "Drought risk assessment using remote sensing and GIS techniques," Arabian Journal of Geosciences, vol. 7, no. 1, pp. 3553, 2014.

[20] D. Wu, D.-H. Yan, G.-Y. Yang, X.-G. Wang, W.-H. Xiao, and H.-T. Zhang, "Assessment on agricultural drought vulnerability in the Yellow River basin based on a fuzzy clustering iterative model," Natural Hazards, vol. 67, no. 2, pp. 919-936, 2013.

[21] P. Han, P. X. Wang, S. Y. Zhang, and D. H. Zhu, "Drought forecasting based on the remote sensing data using ARIMA models," Mathematical and Computer Modelling, vol. 51, no. 1112, pp. 1398-1403, 2010.

[22] R. N. Sahoo, D. Dutta, M. Khanna, N. Kumar, and S. K. Bandyopadhyay, "Drought assessment in the Dhar and Mewat districts of India using meteorological, hydrological and remote-sensing derived indices," Natural Hazards, vol. 77, no. 2, pp. 733-751, 2015.

[23] S. M. Vicente-Serrano, D. Cabello, M. Tomás-Burguera et al., "Drought variability and land degradation in semiarid regions: assessment using remote sensing data and drought indices (1982-2011)," Remote Sensing, vol. 7, no. 4, pp. 4391-4423, 2015.

[24] Z. Sun, J. Zhang, Q. Zhang, Y. Hu, D. Yan, and C. Wang, "Integrated risk zoning of drought and waterlogging disasters based on fuzzy comprehensive evaluation in Anhui Province, China," Natural Hazards, vol. 71, no. 3, pp. 1639-1657, 2014.

[25] W. Pei, Q. Fu, D. Liu, T.-X. Li, and K. Cheng, "Assessing agricultural drought vulnerability in the Sanjiang Plain based on an improved projection pursuit model," Natural Hazards, vol. 82, pp. 683-701, 2016.

[26] J. F. Chen, G. Y. Liu, and H. M. Wang, "Risk measurement of drought disaster during 2000-2009 in Huaihe River Basin, China," Research Journal of Chemistry and Environment, vol. 16, no. s1, pp. 1-10, 2012.

[27] Q. Li, J. Zhou, D. Liu, G. Tang, and Q. Zou, "Disaster risk assessment based on variable fuzzy sets and improved information diffusion method," Human and Ecological Risk Assessment, vol. 19, no. 4, pp. 857-872, 2013.

[28] D. Zhang, G. Wang, and H. Zhou, "Assessment on agricultural drought risk based on variable fuzzy sets model," Chinese Geographical Science, vol. 21, no. 2, pp. 167-175, 2011.

[29] E. L. Guo, J. Q. Zhang, X. H. Ren, Q. Zhang, and Z. Sun, "Integrated risk assessment of flood disaster based on improved set pair analysis and the variable fuzzy set theory in central Liaoning Province, China," Natural Hazards, vol. 74, no. 2, pp. 947$965,2014$.

[30] W. Ouyang, Y. Q. Yu, J. L. Jin et al., "Risk assessment model of drought disaster based on information diffusion and bootstrap: 
a case study in Anhui," Journal of Catastrophology, vol. 30, no. 1, pp. 228-234, 2015 (Chinese).

[31] L. Wang and L. C. Jiao, "The immune evolutionary algorith," in Proceedings of the 3rd International Conference on KnowledgeBased Intelligent Information Engineering Systems, pp. 99-102, Adelaide, Australia, September 1999.

[32] Z.-Y. Li, J.-Y. Wang, and H.-Z. Cheng, "Universal exponential formula for underground water assessment base on immune evolutionary algorithm," Advances in Water Science, vol. 19, no. 5, pp. 707-713, 2008.

[33] C. Guo, Z. Y. Li, and Y. Dang, "Runoff prediction application of BP neural network model based on immune evolutionary algorithm," Water Resources Protection, vol. 25, no. 5, pp. 1-4, 2009 (Chinese).

[34] Q. Fu and X. Y. Zhao, Theory and Practice of PP Model, Science Press, Beijing, China, 2007 (Chinese).

[35] C. Zhang and S. Dong, "A new water quality assessment model based on projection pursuit technique," Journal of Environmental Sciences, vol. 21, supplement 1, pp. S154-S157, 2009.

[36] C. J. Ni, J. Ding, and Z. Y. Li, "Immune evolutionary algorithm," Journal of Southwest Jiaotong University, vol. 38, no. 1, pp. 87-91, 2003 (Chinese).

[37] J. D. Wang and C. F. Huang, "Information diffusion method relevant in fuzzy information processing and its application," Journal of Northwest University, vol. 22, no. 4, pp. 383-392, 1992 (Chinese).

[38] S. He, J. D. Wang, H. Wang, and X. M. Han, “The evaluation of loess slope stability based on combination of information diffusion theory and BP neural network," Journal of Northwest University, vol. 38, no. 6, pp. 983-988, 2008 (Chinese).

[39] C. F. Hung and J. D. Wang, Fuzzy Information Optimization Technology and Its Application, University of Aeronautics \& Astronautics Press, Beijing, China, 1995 (Chinese). 

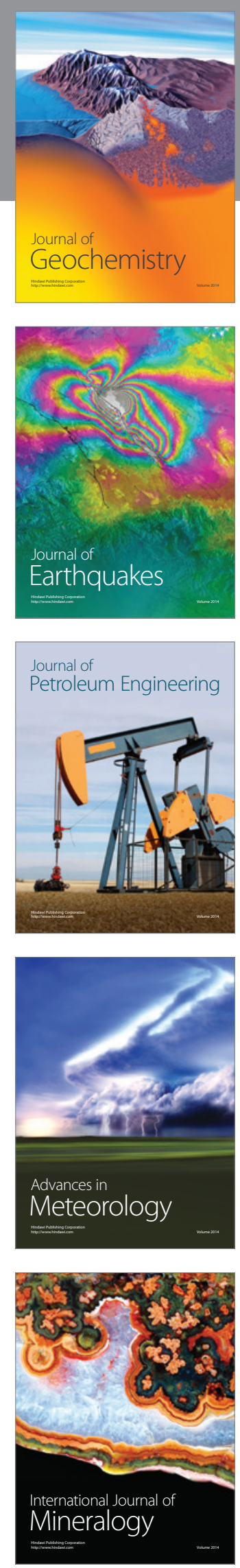
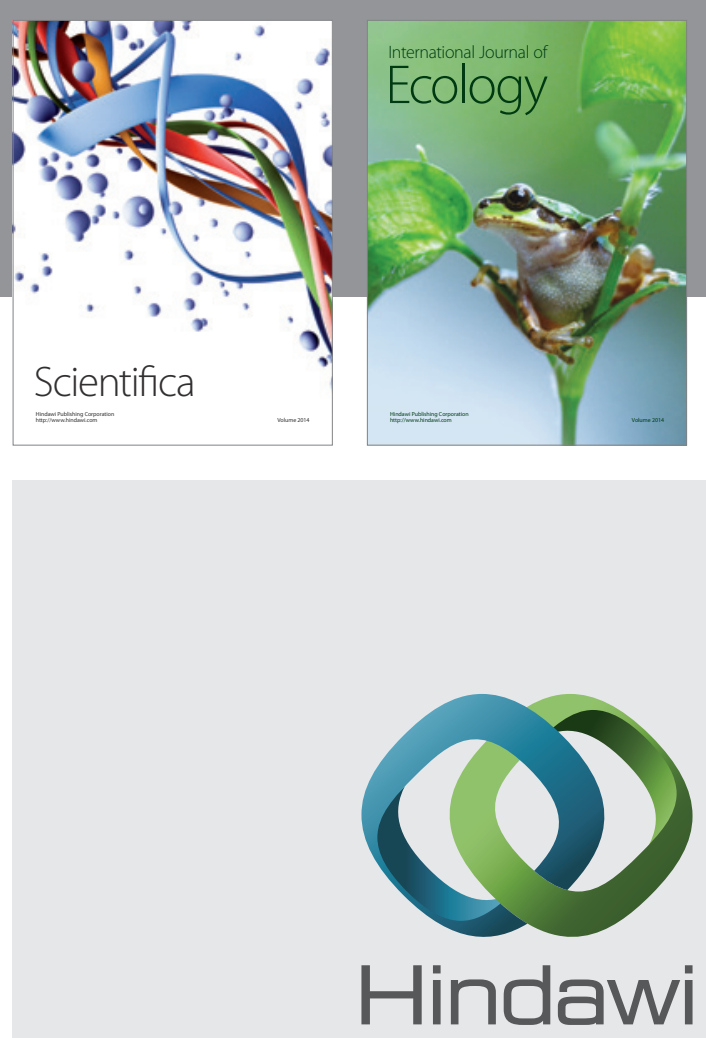

Submit your manuscripts at

http://www.hindawi.com
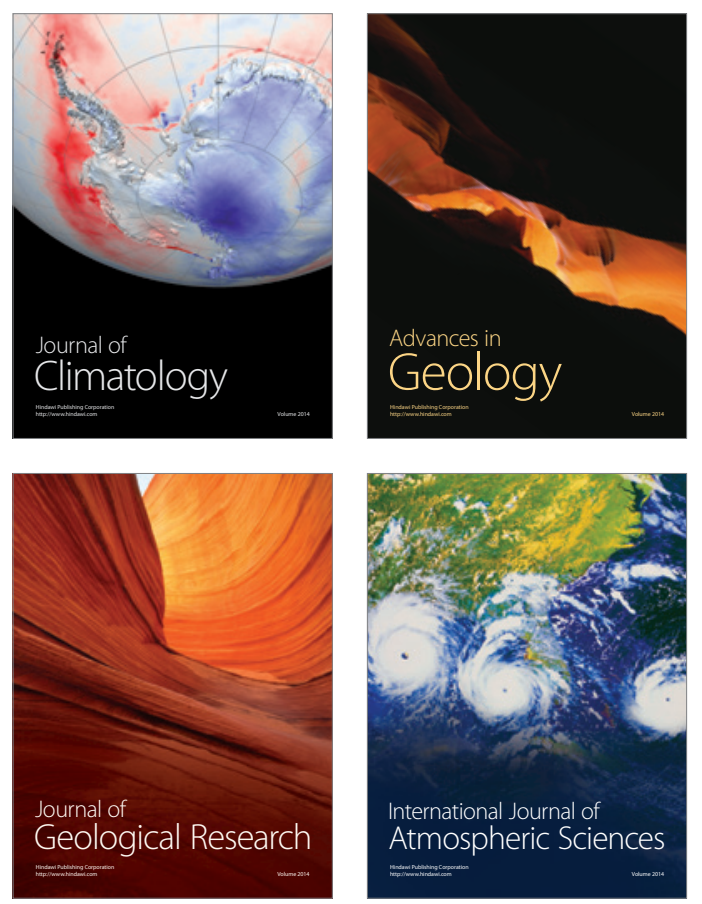

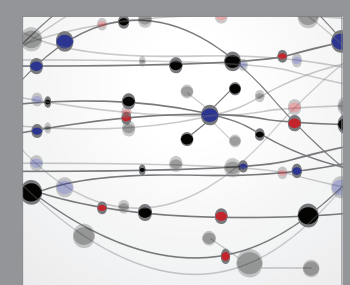

The Scientific

\section{World Journal}
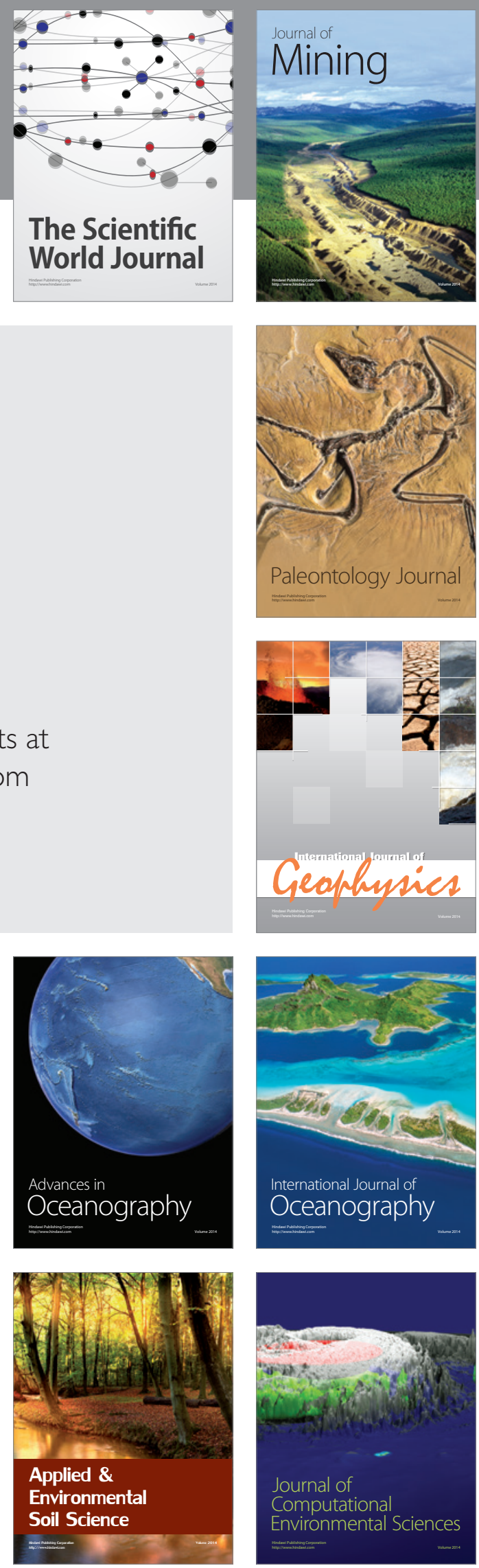